arrangement, which will I hope reassure those of my colleagues who are opposed to patients actually paying for part of their health care costs.

There is, however, a far more important principle than the administrative details of a uniform claim form, and it is obscured by the long list of possibles in appendix B. Each time a patient consults a doctor, at home or in the surgery, whether this is initiated by the patient or the doctor and whether the patient is a temporary resident or not, young or old, with a trivial or serious complaint, an encounter takes place at which the doctor uses his or her skills to provide a service to the patient. Two minutes is enough for diagnosis and treatment of tonsillitis or scabies, or the review of a hypertensive case. It can take 20 minutes to elicit the history and examine properly the patient with spinal pain, half an hour or more to determine the relevant features of a depressive illness; further examples are unnecessary, for I hope the point is clear. What should be recognised, and I believe the working group has failed in this, is that every consultation, regardless of its content of listening, physically examining, and technically testing or treating, is an item of service for which payment should be made to the doctor.

We have reached a watershed in general practice after 30 years of the NHS and I urge my colleagues to think very seriously about this proposition, and press their local LMCs to carry it to the special conference. The design of a claim form, the duration of consultations for which different payments would be made, the inclusion of other special procedures from appendix $B$, and the size of the consultation fees are very important details which would require to be worked out in negotiations with the Health Department; but contemplation of the details should not at this stage be allowed to obscure the fundamental concept which I have outlined. We have an opportunity with the charter to introduce this enduring and truly work-sensitive feature into the remuneration of general practice; it would be a pity not to try.

Dechmont, West Lothian

R M MILNE

\section{Nurse training}

SIR,-The introduction of the EEC nursing directives on nurse training and GNC policy based on them will have very considerable financial implications for hospitals with training schools. In the Peterborough Health District the cost, when the policy is fully implemented, will at present-day prices he some $£ 124000$.

This money represents the cost of the extra salaries of staff to be employed to meet the new regulations; they are:

$$
\begin{aligned}
& 18 \text { staff nurses } \\
& 2 \text { nursing auxiliaries }
\end{aligned}
$$

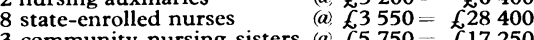

$$
\begin{aligned}
& \text { Total } \overline{£ 124050}
\end{aligned}
$$

This sum of money represents, for example, the annual development money for the health district for the current financial year.

The DHSS has stated that no extra money is to be made available to cover the cost of implementation of the regulations. The Medical Executive Committee is most concerned that there would seem to be no alternative but to conform to the regulations, thus taking a large amount of money from an already overstretched budget.

\section{G G CRABbE} Medical Executive Committee

Peterborough District Hospital,
Peterborough, Cambs PE3 6DA

\section{Ophthalmic services in the NHS}

SIR,- - The apparently low fee for sight testing by an ophthalmic medical practitioner (OMP) which concerns Mr C Cockburn (24 March, $\mathrm{p} 825$ ) and others is not difficult to understand.

There are about 950 OMPs in the National Health Service, $28 \%$ of whom are also consultant ophthalmologists. As there are about 380 consultant ophthalmologists in the Service about $70 \%$ of consultant eye surgeons undertake work as OMPs. It would therefore seem reasonable that the remuneration for these two activities be kept in line.

A full-time consultant ophthalmologist at the top of the incremental scale receives payment of $£ 24.41$ per notional session. In his outpatient clinic he is expected to make farreaching decisions concerning the medical and surgical treatment of a considerable number of patients to help those he can and to support those with irremediable eye disease. An OMP undertaking a session of 11 sight tests receives a net payment of $£ 23 \cdot 10$, and with expenses $£ 30 \cdot 25$. Responsibility for abnormalities other than refractive errors have to be referred elsewhere. The present situation is therefore that it is financially slightly more rewarding to work as an OMP than as a consultant ophthalmologist.

Any increase in OMP remuneration would result in an increased differential adverse to the consultant and would highlight the low esteem in which the NHS holds its senior doctors. Yes, Sir, something can be done. Recognise the value of the consultant in all specialties and the rest would follow.

\section{Basingstoke, Hants RG23 8HA}

\section{David Moss}

***The Secretary writes: "While we accept that the remuneration of a consultant is far too low, we could not agree that it would normally be possible to undertake 11 sight examinations under the general ophthalmic services in the equivalent of an NHS session (three and a half hours). An independent timing study has shown that the total average time involved for each examination (excluding administration time by ancillary staff) is in the region of 24-25 minutes. The number of tests which could normally be carried out in an 'NHS session' would therefore be eight and not 11 . This would give a 'sessional rate' of $£ 16 \cdot 80$." - ED, $B M \mathcal{~}$.

SIR,-May I amplify the point raised by Dr J L Reis (24 February, p 559) and Mr Charles Cockburn (24 March, p 825) concerning the discrepancy in remuneration of ophthalmic opticians and ophthalmic medical practitioners under the General Ophthalmic Service?

We are told by the DHSS that the sight testing portion of the fee paid to the doctors is actually higher than that paid to the ophthalmic opticians but that the total payment per test made to the latter has to be more because of their greater overhead expenses. Now that ophthalmic opticians are allowed to practise alongside the doctors in medical eye centres one wonders whether these opticians are still paid the higher fee. If they are then I agree with $\mathrm{Mr}$ Cockburn that it is a scandal.

Shirley, Surrey CR0 7UA

P JOAN BISHOP

\section{Accident and emergency services}

SrR,-Mr Walpole Lewin's report to the Joint Consultants' Committee on the staffing of accident and emergency departments has provoked considerable interest. The JCC poses several questions for consideration by regional staff committees (18 November 1978, p 1447). As a group undertaking specialty training in this new discipline at senior registrar level, may we offer some pertinent comments on these questions in the light of our collective experience?

Should all accident and emergency departments have effective consultant supervision? Yes. We should like to see these consultants trained and accredited in the future in accident and emergency medicine.

Should the accident and emergency departments be staffed mainly by SHOs with senior registrars in suitable departments for training but with no registrar posts? No. The present arrangement whereby we are each working a training programme flexible to our individual needs is a very welcome advance but should be considered a stop-gap measure. The existing programme has its problems. For example, it is difficult for a senior registrar with a surgical background to assume the role of an SHO in medicine. Such a secondment intermittently leaves the accident and emergency department without its senior registrar. Secondment to other departments would be better at registrar level.

Should there be a specialist diploma in accident and emergency work? Yes. As a development, we would like to see faculty status afforded to the discipline of accident and emergency medicine and the responsibility for the entire training programme from house officer through to consultant vested in an appropriate college. A higher diploma would then come at registrar level, as it does with the FFA and the FRCS.

Should there be a moratorium on medical assistant posts in accident and emergency departments? Yes.

Should there be a general policy of having accident and emergency subcommittees? The consultant should have available to him effective representation on the medical executive committee and with other divisions. Where this does not exist we would favour the establishment of accident and emergency subcommittees.

Should the accident and emergency consultant be an "admissions officer" for the hospital? Patients sent up by their general practitioner for emergency admission should be dealt with by the specialist firm on duty. Nevertheless the "admissions unit" should be adjacent to the accident and emergency department.

Should most major departments have shortstay beds in the unit? All major departments should have short-stay beds in the unit under the clinical control of the accident and emergency consultant.

Should most small accident and emergency departments be progressively closed? Most small urban accident and emergency departments should be progressively closed, leaving mainly large departments with over 20000 new cases per year. Peripheral services should be 